\title{
Investigating Heat Loss through Vestibule Doors for a
}

\author{
Non-Residential Building \\ Patrick Maxwell $^{1}$, Faisal Durrani ${ }^{2 *} \&$ Mahroo Eftekhari $^{2}$ \\ ${ }^{1}$ British Board of Agrément, Bucknall's Lane, Watford, Hertfordshire, UK \\ ${ }^{2}$ School of Civil and Building Engineering, Loughborough University, Leicestershire LE11 3TU, UK \\ *Faisal Durrani, E-mail: F.Durrani@lboro.ac.uk
}

\begin{abstract}
The aim of this study was to investigate the effects of air flow movement through high use front entrance doors of a college building with large flows of people. The objectives were to visualize and quantify the resultant energy losses through the entrance doors, coupled with investigating any potential improvements that can be obtained through improved design. The findings of the study suggest that the heat loss from the front entrance design can contribute to up to $2.8 \%$ of the buildings' energy loads. It was also seen that a vestibule creates a tunnel effect for cold ambient air to enter the building without hot air escaping from the vestibule. Rather hot stale air exits through openings at the ceiling height. Potential solutions with entrance design are investigated and their results compared to the outcomes of a similar model designed using Computational Fluid Dynamics (CFD).
\end{abstract}

\section{Keywords}

vestibule design, building thermal simulation, experimental measurements, air flow visualization, computational fluid dynamics

\section{Introduction}

Exterior doors and entrances of non-residential buildings can be major sources of energy losses. Air infiltration or exfiltration due to the frequent use of doors contributes to this phenomenon, coupled with pressure differences across each door, created by the wind, stack effect or ventilation systems.

Early designs of revolving doors were seen in the late 1800's, but only in 1970's due to the oil crisis, the revolving doors became more popular. One of the requirements with revolving doors is fitting of a separate door for disabled access. Stalder (2009) discussed the revolving doors and legislation requirement for disabled access. Although revolving doors were seen as an ideal solution to energy conservation, Schijndel et al. (2003) identified that further research is required to compare the energy saving from revolving to sliding doors. However, it further identified that revolving doors are effective solutions for retaining heat in buildings, but are less suited for handling the large flows of people.

To establish the challenges faced by organizations expecting heat loss from high use doors with large flows of people, a typical focus of investigation would be the airports and supermarket industry. Major 
supermarkets have rolled out a program for store extensions to front entrances in order to reduce energy losses. Allard (1998) suggests that an average of 36\% to 51\% of air acting on the external doors will flow into the main body of a store. Lawton (1995) explained the effect of air curtain and air movement over an open doorway and McNally (2008) discussed the importance of designing air curtains for effective use with conventional or high speed roller shutters. These studies followed Holzhauer (1986) qualifying the resultant increased heating loads owing to large doors remaining open for periods of time.

In a study by Wan (2009), the air leakage through automatic doors was calculated. This involved investigating a UK hospital with wind and stack, using two separate entrances with automatic sliding doors. Yuill et al. (2000) discovered differing air flow coefficients dependent on vestibule arrangements and dimensions. Airflows in vestibules could then be considered with the varying states of sliding door openings. However, Cho et al. (2010) investigated the potential energy savings established from adding a vestibule to entrances. It concluded that although building energy software had the potential to calculate the energy impact of door openings efficiently, there were few studies on how to model the doors. Artman et al. (2010) calculated heat flows across doorways with an air curtain and wind lobby. This was established through calculating heat flow based on temperature and velocity data obtained from a Computational Fluid Dynamic (CFD) model. The CFD model was evaluated against real temperature data which was collected on site of a typical supermarket.

Yan (2010) and Chen (2011) investigated a college's post occupancy energy performance. They noted the heavy traffic of staff and students entering or leaving the building through the building's sole entrance sliding doors and assumed that subsequent heat losses were being incurred. They also observed the large entrance opening aperture, coupled with the heavy traffic, causing both potential heat losses and thermal sensations of discomfort for the occupants working in the areas of the front entrance and reception. The discomfort of the occupants was not offset by the air curtain fan operating in the entrance area designed to counteract cold air entering the building. This would study the potential of the carbon energy loads being increased by the heat losses incurred through the common design of the front entrance.

Therefore, in order to analyze the effects of resultant energy losses through the entrance door design forming a vestibule with large flows of people, a College in Leicestershire, UK, was selected. This building was also chosen because of the added opportunity to consider its internal atria and potential of any impact from stack effects.

\section{Method}

\subsection{Case Study College Background}

The case study College building is a modern further education college constructed in 2005 with an extension opened in 2007. The building occupies an area of $16000 \mathrm{~m}^{2}$. It is ventilated through mixed mode, with electricity and gas heating the air supply, under floor heating and radiators.

Published by SCHOLINK INC. 
A "street" forms an open spine the whole length of the building. With the exception of an atrium, opening windows are incorporated into the top of the "spine" of the building to release stale air. The College front entrance is the only authorized entry into the building. The energy efficiency rating of the College building is of a "C" SAP rating, which denotes "good" for the age of the building.

Replacing entrance doors with revolving doors was discounted by the College following its own consultation with other college facilities managers owing to the high footfall and the maintenance issues rendering the concept uneconomical. A vestibule forms the font entrance with a volume of the $40.42 \mathrm{~m}^{3}$. Located at both ends of the chamber are two double sliding doors, which when open, present an aperture of $3.675 \mathrm{~m}^{2}$. The street is open to ceiling level and provides access to the whole building. Consequently, air flow can move unhindered from the southern to the northern end.

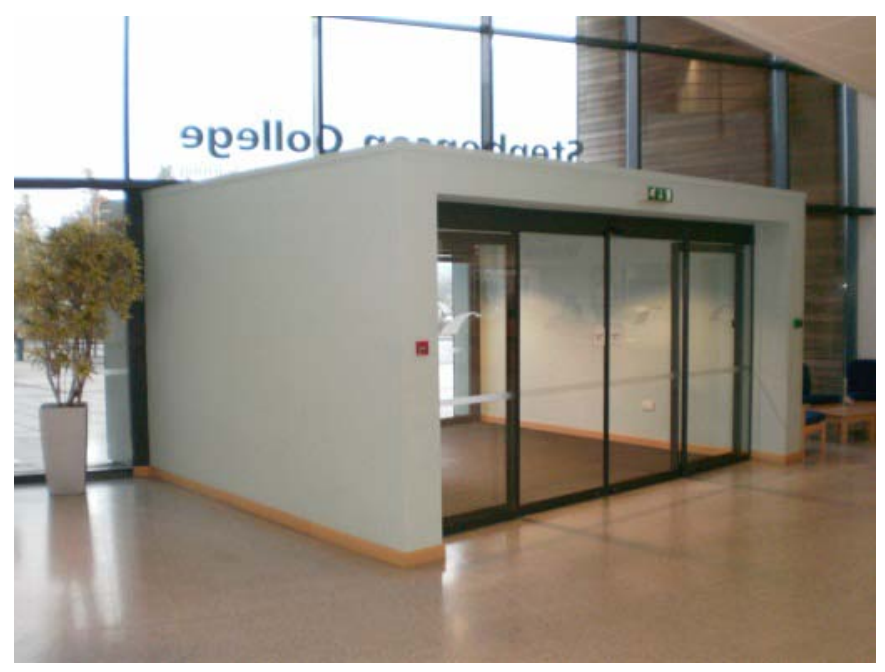

Figure 1. Image of the Front Entrance "Vestibule"

\subsection{Initial Investigation Method}

The early part of the study concluded that sliding doors were a more favored option for buildings with high volume and high occupancy. Chen (2011) investigated the college's post occupancy energy performance. This study observed the large entrance opening aperture, coupled with the heavy traffic, causing both potential heat losses and thermal sensations of discomfort for the occupants working in the areas of the front entrance and reception. The discomfort of the occupants was not offset by the air curtain fan operating in the entrance area designed to counteract cold air entering the building. This would study the potential of the carbon energy loads being increased by the heat losses incurred through the common design of the front entrance.

\subsubsection{Understanding Air Flow Movement}

In order to analyse the behaviour of the airflow movement in the College building understanding it visually and calculating the quantity required experimentation. To observe the behaviour and direction of air the movement, a smoke machine was used to mix with the outside air and understand its Published by SCHOLINK INC. 
movement from outside to inside the building. The smoke test was conducted with the assistance of the maintenance team of the College.

Video cameras were strategically placed to allow a panoramic internal view from the entrance to other open areas of the College. The cameras captured the smoke infiltration from both angles of the inside of the entrance to the building. The outside weather was recorded and shown in Table 1.

\section{Table 1. External Weather Conditions During Smoke Test 14.02.2012}

\begin{tabular}{ll}
\hline Outside Dry Air Temperature & $2.9^{\circ} \mathrm{C}$ \\
\hline Wind Direction & North West \\
Wind Speed & $3.22 \mathrm{~m} / \mathrm{s}$ \\
Outside Air Pressure & $1028.1 \mathrm{bar}$ \\
\hline
\end{tabular}

In order to establish a condition where only natural air flows could be observed, the HVAC plant was isolated for the duration of this experiment. Once commenced, the smoke initially blew across the face of the front entrance doors whilst in a closed position and started to rise up across the face of the building. Once the path of the smoke was established, within 15 seconds of the doors opening, the vestibule started to fill with smoke. With the increased regularity of the doors being opened, the more the smoke filled the vestibule. After a further 35 seconds, smoke flowed into the building as a constant stream, then under increasing velocity. The smoke spread across the open areas internally maintaining a distribution at low level. No airflow was observed to travel outside through the doors.

Playback of the videos demonstrated that once the smoke had completely filled the vestibule from outside, it then "tumbled" into the College foyer area. It then remained at a lower level at a height of approximately $1.2 \mathrm{~m}$. Thus stratification was evident and the smoke travel was one directional from outside the building to inside. Irrespectively if the two door sets did not open at the same time, the vestibule still filled with smoke and entered the building when the internal set of doors opened and continued to do so when the outer doors were closed. This established that further experimental investigation would be required to quantify the heat losses through the entrance.

\subsubsection{Calculating Air Movement and Heat Loss Energy}

An analogue anemometer was used to measure the air flow velocity through the vestibule. Door contactors were connected to both automatic doors and data loggers to measure the open and close duration and frequencies. Also a minimum opening duration of the opening of the inner door would assist in calculating steady state calculations. Data loggers also recorded the dry bulb air temperatures externally in a shaded location and internally; in the vestibule and entrance foyer. For the foyer monitoring, a probe was positioned on a column at a height of $1.1 \mathrm{~m}$ above the finished floor level $5.8 \mathrm{~m}$ from the entrance. This location was earlier seen to be affected by the smoke in the video.

As weather could impact the airflow into the building, local weather monitoring from the College's 
annually calibrated weather station collected data every 30 minutes. The station's anemometer measured both wind speed and direction. Quantitative energy measurements were collected from the College's online remote data facility of natural gas and electricity consumption. The fuel consumption for the whole College at any time could be analysed to observe patterns and linkages to overall activity. Fixed monitoring equipment recorded data for a two week period commencing on Monday $27^{\text {th }}$ February 2012 including the movement of the entrance doors and the external/internal dry air temperatures. The busiest time of the College activity in the entrance was identified by the staff working in the reception, which experienced the discomfort in thermal sensation. This was identified as Monday mornings between 08.30 and $09.00 \mathrm{hrs}$. This period was monitored using a mobile anemometer in the foyer, just inside the vestibule. An aggregate was used in these periods to measure the airflow velocity.

\section{Results}

\subsection{Results from Data Collection}

The overall data analysis of the temperature probes and door contactors was restricted to the College building's occupation period of 08.00-21.00 hours Monday to Thursday and 08.00-17.00 hours on Fridays.

Building heating set point for the street location was $19^{\circ} \mathrm{C}\left(+/-1^{\circ} \mathrm{C}\right)$. Table 2 illustrates the temperature differences from the foyer to the outside temperatures, then the foyer to the inside temperatures. The foyer to outside $\Delta \mathrm{T}$ appear to have a constant difference $\left(+/-1^{\circ} \mathrm{C}\right)$, whilst the foyer to inside $\Delta \mathrm{T}$ appear to reflect the changes in the outside conditions, i.e., the colder the conditions outside, the larger temperature differential could be seen between the entrance area and the main body of the building. This outcome might explain some of the relationship of the sensations of thermal discomfort experienced by the reception staff.

The experimental data used for heat loss calculation through the entrance doors is also shown in Table 2. The wind direction or velocity appeared to have an impact on the airflow velocity measured just in the foyer through either increasing velocity by $0.5 \mathrm{~m} / \mathrm{s}$ or by switching direction from a south westerly to a north or north westerly. This is seen from a snapshot sample of three separate days.

Table 1. Experimental Temperature and Air Flow Data

\begin{tabular}{llll}
\hline Reading and location & 27.02 .2012 & 05.03 .2012 & 12.03 .2012 \\
& 008.30 & $@ 08.30$ & $@ 08.30$ \\
\hline Outside temperature & 7.2 & 4.1 & 5.2 \\
Foyer temperature from probe & 17.8 & 13.9 & 14.4 \\
T of foyer to outside temperatures & 10.6 & 9.8 & 9.2 \\
Inside temperature from probe & 19.9 & 18.7 & 19.6 \\
\hline
\end{tabular}


$\mathrm{T}$ of foyer to inside temperatures

Airflow velocity in foyer entrance; (mean taken from anemometer)

Wind velocity from exposed weather station

Wind direction from exposed weather station

$\begin{array}{lll}-2.1 & -4.8 & -5.2 \\ 0.5 \mathrm{~m} / \mathrm{s} & 1.0 \mathrm{~m} / \mathrm{s} & 0.5 \mathrm{~m} / \mathrm{s} \\ 1.3 \mathrm{~m} / \mathrm{s} & 3.6 \mathrm{~m} / \mathrm{s} & 1.8 \mathrm{~m} / \mathrm{s} \\ \text { WSW } & \mathrm{N} & \text { WNW }\end{array}$

In order to analyze the effects further, a comparison was considered with the effects of the wind on the temperatures experienced inside the building. Table 3 demonstrates the impact of the wind velocity or direction over two separate days.

Table 2. Summary of Wind Velocity and Direction

\begin{tabular}{lll}
\hline Reading date and time & Wind Velocity & Wind Direction \\
\hline & $2.01 \mathrm{~m} / \mathrm{s}$ & $\mathrm{W}$ \\
$05.03 .2012 @ 09.00$ & $4.19 \mathrm{~m} / \mathrm{s}$ & $\mathrm{N} / \mathrm{NE}$ \\
\hline
\end{tabular}

The temperature variations for the stated weather conditions are shown in Figures 2 and 3. The main internal temperature is generally stable throughout the occupancy period. The external temperatures demonstrate much lower temperatures. However, the graph of Figure 3 illustrates a much larger temperature difference (average of $5^{\circ} \mathrm{C}$ ) between the foyer and the internal temperature in comparison to the average temperature difference of $1^{\circ} \mathrm{C}$ in Figure 2. In addition, the foyer temperature is fluctuating throughout the day. This suggests that effects of a wind direction change aimed at the front entrance coupled with a stronger wind velocity of $4.19 \mathrm{~m} / \mathrm{s}$ had an impact on the foyer temperature fluctuations.

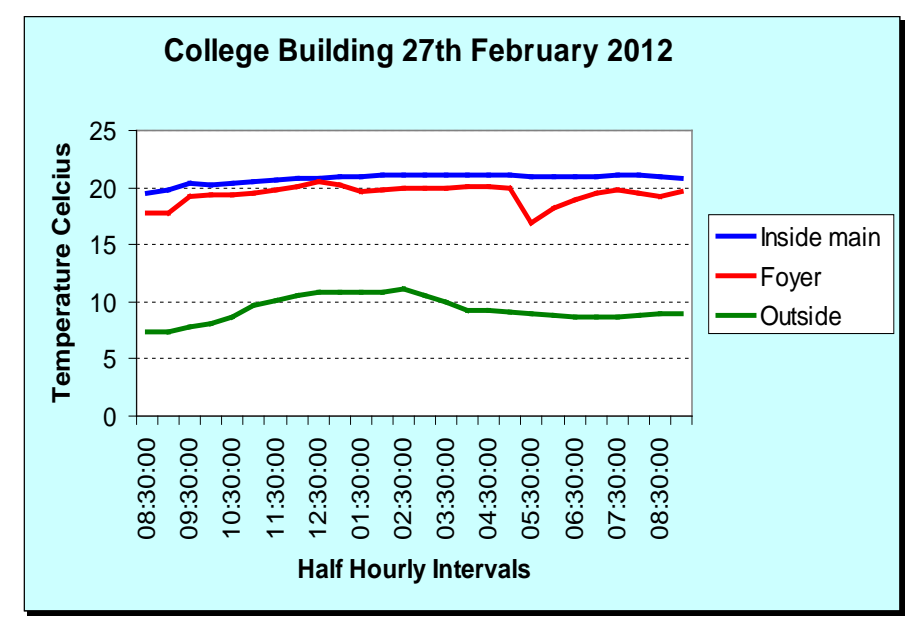

Figure 2. Collected Occupancy Temperatures for 27.02.12 


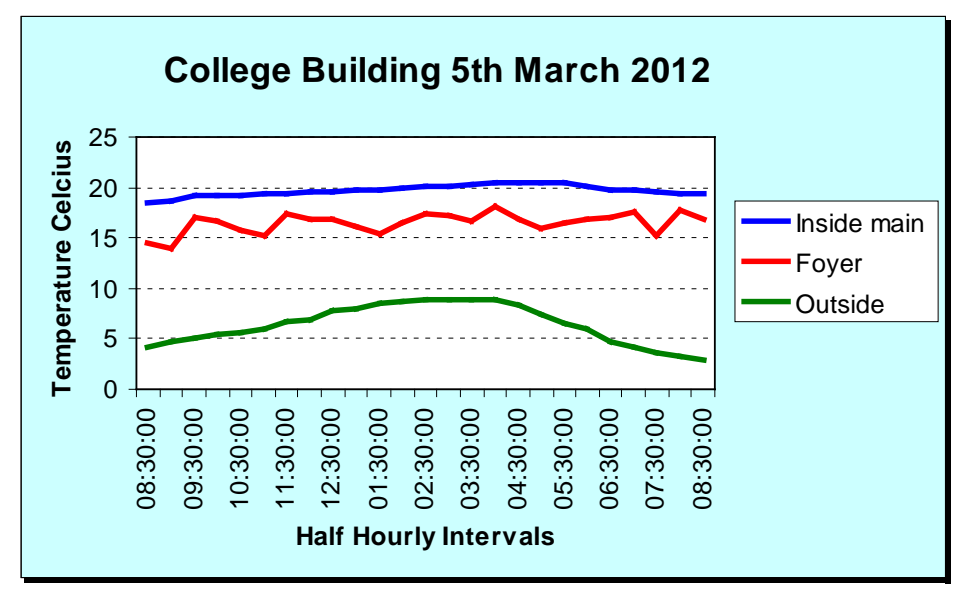

Figure 3. Collected Occupancy Temperatures for 5.03.12

A steady state heat loss method was chosen to calculate the heat loss from the building entrance doors.

To complete the calculations, a mean of the temperatures for inside and outside the building was established as $\mathrm{T}_{0}=8.27^{\circ} \mathrm{C}$ and $\mathrm{T}_{\mathrm{i}}=20.83^{\circ} \mathrm{C}$. The heat loss via ventilation can be expressed as:

$\mathrm{Q}_{\mathrm{v}}=\mathrm{C} \rho \mathrm{q}\left(\mathrm{T}_{\mathrm{i}}-\mathrm{T}_{\mathrm{o}}\right)$

where;

$\mathrm{C}=1.03 * 10^{3} \mathrm{~J} /(\mathrm{kg} \cdot \mathrm{K})$

$\rho=1.2929 \mathrm{~kg} / \mathrm{m}^{3}$

$\mathrm{q}=1.8375 \mathrm{~m}^{3} / \mathrm{s}$

$\mathrm{T}_{\mathrm{i}}=20.83^{\circ} \mathrm{C}$

$\mathrm{T}_{\mathrm{o}}=8.27^{\circ} \mathrm{C}$

$\Delta \mathrm{T}=12.56^{\circ} \mathrm{C}$

The steady state ventilation heat loss was calculated as: $\mathrm{Q}_{\mathrm{v}}=30734 \mathrm{~W}$.

With the location of the building being in the Midlands, a judgment was made to consider a thirty-six week heating season. The College students also have breaks with half terms and traditional holidays. These total six weeks through the heating season. As this was not measured during this period, these weeks have been discounted from the study. Therefore the total hours of doors operating over a representative heating season during full occupancy was established as 1830 hours.

The door contactors offered variable data. With an overview of the readings, Monday $27^{\text {th }}$ February was considered an average day. The doors opened and closed on 1963 occasions from $08.00 \mathrm{hrs}$ to $21.00 \mathrm{hrs}$. The contactors were open for a total time of $8315 \mathrm{~s}$. As the doors open and close at $1 \mathrm{~m} / \mathrm{s}$, it is clear that it would take $1 \mathrm{~s}$ for the doors to open and close.

As Qv=30734 W and the operational hours of the doors=1830hrs, then;

(30 734W x 1 830hrs)/488s=115 252.5Wh

Therefore the minimum potential heat loss through the front entrance doors could be a minimum of $115.25 \mathrm{kWh}$. Reflecting on the velocity of the smoke in the video through the building entrance, if the Published by SCHOLINK INC. 
steady state calculation was increased to a reasonable $1.0 \mathrm{~m} / \mathrm{s}$, the potential heat loss through the front entrance doors would be considered to be $230.5 \mathrm{kWh}$ during a heating season.

The heating strategies use both electricity and gas, the monitoring system cannot distinguish between the utility consumption rates. Therefore generic and overall utility consumption energy data was collected as shown in Table 4. The fuel energy loss would equate to heat loss/system efficiency. Therefore, judging on the age of the building an assumption was made that rated the overall system efficiencies at $80 \%$. As the fossil fuel related energy that has been displaced from the front entrance doors cannot be identified, heat loss options and comparison were illustrated. Table 4 illustrates the front entrance heat loss against the total energy loss based on total electricity or gas consumption.

Table 3. Impact of Front Entrance Heat Loss against Total Net Building Energy Loss

\begin{tabular}{|c|c|c|c|c|}
\hline $\begin{array}{l}\text { Utility data readings: } \\
01.10 .2011 \text { to } 30.04 .2012\end{array}$ & kWh & $\begin{array}{l}\text { Fuel energy loss } \\
(\mathrm{kWh} \times 80 \%)\end{array}$ & $\begin{array}{l}\text { Based on heat loss } \\
\text { of } 115.25 \mathrm{kWh}\end{array}$ & $\begin{array}{l}\text { Based on heat loss } \\
\text { of } 230.5 \mathrm{kWh}\end{array}$ \\
\hline Electricity Consumption & 926195 & 740956 & $0.16 \%$ & $0.31 \%$ \\
\hline Total Gas Consumption & 104158 & 83326 & $1.4 \%$ & $2.8 \%$ \\
\hline
\end{tabular}

To measure the carbon element of the fuel cost of the front entrance losses, Defra/DECC conversion factors were used. Table 5 illustrates the impact of the $\mathrm{CO}_{2}$ on the heat energy lost through the front entrance based on the average air flow velocity of 0.5 or $1.0 \mathrm{~m} / \mathrm{s}$ with either electricity or gas consumption.

Table 4. Impact of Front Entrance Heat Loss on $\mathrm{CO}_{2}: 1$ Based on 0.5m/s; 2 Based on 1.0m/s Gas

\begin{tabular}{llll}
\hline \multirow{2}{*}{$\begin{array}{l}\text { Fuel to } \mathrm{CO}_{2} \text { based on heat } \\
\text { loss through building }\end{array}$} & $\begin{array}{l}\text { Based on heat loss of } \\
\mathrm{CO}_{2} \text { factor of fuel }\end{array}$ & $\begin{array}{l}\text { Based on heat loss } \\
\text { of 230.5kWh }\end{array}$ \\
\cline { 2 - 4 } entrance & $\mathrm{kgCO}_{2} / \mathrm{kWh}$ & $\mathrm{kgCO}_{2}$ & $\mathrm{kgCO}_{2}$ \\
\hline Electricity & 0.49072 & 56.56 & 113.11 \\
Gas & 0.18483 & 21.30 & 42.60 \\
\hline
\end{tabular}

Using the data, potential heat loss outcomes were compared to the whole buildings' energy consumption. This was used to offer some validation of the outcomes demonstrated. Further calculations were undertaken to consider the buildings' $\mathrm{CO}_{2}$ emissions with respect to airflow into the front entrance and hot air displacement in the building as shown in Table 6.

Table 5. Range of Results Following Data Analysis of Experimental Investigations

\begin{tabular}{llll}
\hline Range of outcomes & Front entrance & Front entrance heat loss (kWh) in comparison to & $\mathrm{kgO}_{2}$ \\
over period: & heat loss & the fuel energy consumption of building & \\
\hline
\end{tabular}




\begin{tabular}{llll}
\hline $\begin{array}{l}01.10 .2011 \\
30.04 .2012\end{array}$ & to & & \\
\hline From & & & 21.30 \\
To & $115.25 \mathrm{kWh}$ & $0.16 \%$ & 113.11 \\
\hline
\end{tabular}

\subsection{Building Dynamic Simulation}

Following the earlier video analysis in the front entrance, foyer, atria, café areas and the "street" further analysis was required, as these locations were affected by the smoke test. Integrated Environmental Solutions (IES) Virtual Environment software was selected to investigate airflow modelling through the IES Macroflo package.

The building's original CAD drawings were imported into the IES Modelbuilder. The rooms were all formed along with the floors and connections between the spaces. The fabric of the building was identified for all of the planes involved. Under the IES "Building Template Manager" and "Constructions" the fabric was assembled in the data for use and dissemination later e.g., the windows and walls allocated with appropriate thermal resistance properties.

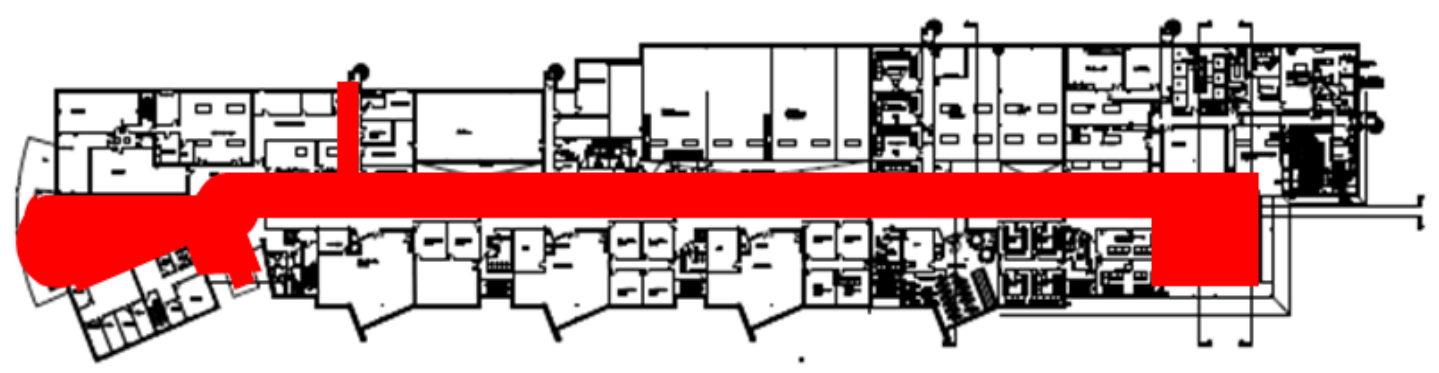

Figure 4. Plan View Schematic of the College Building; Red Areas Denoting Locations Simulated within IES

Sensible and latent heat gains were described in terms of lighting, human occupancy and equipment such as computers. Solar gains would automatically be considered from the orientation of the building and the glazing type, location and size. The infiltration element of the ventilation was set at 1 air change per hour (ach). The mixed mode element of the ventilation was demonstrated through programming the opening windows in the stacks along the "street". Wind and buoyancy pressures were also taken into consideration.

Using macroflo, the opening threshold was set to open at temperatures over $22^{\circ} \mathrm{C}$, replicating those used by the College. The heating strategy was entered into the building template manager with a minimum threshold of $18^{\circ} \mathrm{C}$, and subsequent cooling of $22^{\circ} \mathrm{C}$. The switching points were then established through APpro. The nearest geographical weather file was selected as Birmingham. "Suncast" established the heat and light gains, coupled with any effects of shading. The front entrance 
doors were set as opening windows with College occupancy timings reflected and openable areas of $15 \%$.

\subsubsection{Simulated Front Entrance Designs and Results}

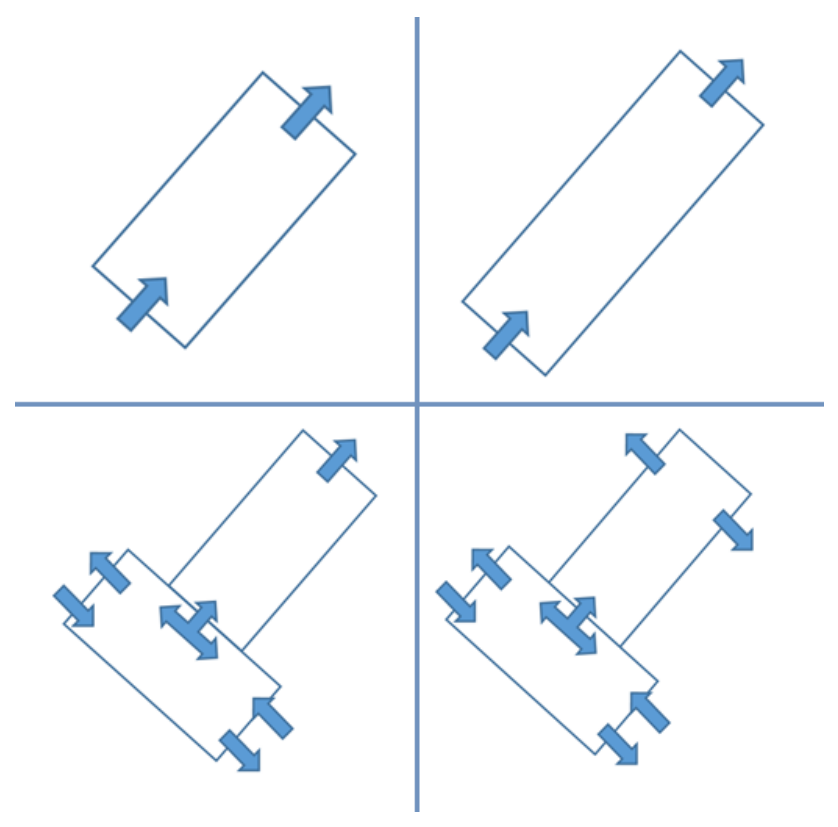

Figure 5. IES Modelled Designs (a) Original Design (b) Extended Existing Design (c) Additional Vestibule Design (d) Additional Vestibule Design with Opposing Doors for Entering Inside

Four concepts, illustrated in Figure 5, were modelled and investigated. The first vestibule concept was the existing design. This could then offer a benchmark against other designs for the heating loads for the building under this concept. The second vestibule design simply extended the length of the original vestibule. The third design introduced a further construction to the outside incorporating a second vestibule and two further pairs of sliding doors. Consequently, resistance increased for any air paths as airflow had to turn $90^{\circ}$ to enter the building. The fourth vestibule design maintained the additional construction of the third vestibule. It removed the internal pair of sliding doors and incorporated two pairs either side of this on the internal walls of the vestibule. Theoretical resistance was further increased to the air path as the airflow had to turn a total of $180^{\circ}$ to enter the building.

Simulations were run after implementing each design, expecting to demonstrate the direct effect of the outside air flow movement into the building through the front entrance. The results demonstrated increases in heat loads as each design was modelled.

For the original design of the vestibule, the building simulation predicted an annual heating load of 1.844MWh. The second vestibule design was predicted to have an annual load of 1.854MWh, an increase of $0.5 \%$. The extended area would equate to $7 \mathrm{~m} \times 4 \mathrm{~m}=28 \mathrm{~m}^{2}$. The subsequent heat load being; $10 \mathrm{kWh} / 28 \mathrm{~m}^{2}=357 \mathrm{kWh} / \mathrm{m}^{2}$.

ECON19 indicates that a typical heat load from this type of building could be up to $201 \mathrm{kWh} / \mathrm{m}^{2}$, Published by SCHOLINK INC. 
suggesting that $357 \mathrm{kWh} / \mathrm{m}^{2}$ was too high. However, this model has two permanently opened doors (15\% opening) at each end to simulate the front entrance air movement. Therefore with such an increase in the inevitable air changes, a significantly higher heat loss from this room could be expected. The third lobby design reduced the length of the first vestibule from the second design and then incorporated a second vestibule to introduce more resistance to the air flow paths as mentioned in CIBSE AM10: 2005. The heating load report predicted 1.867MWh, an increased load against the original design of $23 \mathrm{kWh}$ over the year $(+1.3 \%)$. Again, the heat load increase could be explained by the outcomes of the previous design.

The fourth lobby design further introduced more resistance to the air flow paths. Despite these strategies, the heating load report predicted 1.867MWh. Again, this was an increased load against the original design of $23 \mathrm{kWh}$ over the year $(+1.3 \%)$.

In order to recognise that the various designs would have increased the volume of the building and thus potentially increase the overall energy loads, the first and fourth designs were reprogrammed to make the vestibules unheated spaces. The resultant reports offered no change to the original outcomes.

\subsection{CFD Analysis}

Computational Fluid Dynamics (CFD) has been used widely to analyze natural ventilation. In this research CFD was used to investigate the flow patterns in the building caused by natural ventilation.

\subsubsection{Computational Domain and Boundary Conditions}

A full scale computational domain was built following the plans of the building. However, as with most CFD analysis the geometry was simplified. A hexagonal structured mesh with a resolution of 3 million nodes was employed for this study. The mesh constructed was considered appropriate when mesh independency was achieved. Air was selected as the working fluid. The floor was given the boundary condition of a distributed heat source with a heat input of $20 \mathrm{~W} / \mathrm{m}^{2}$ to represent heat gain in the building. The walls were considered adiabatic and assigned the "no-slip" boundary condition. An Automatic near-wall treatment was used which automatically switches from linear wall-functions $\left(u^{+}=y^{+}\right.$for $y^{+}<11$ ) to a low Re buffer layer region profile $11<y^{+}<30$ and a log-law profile for $y^{+}>30$. In this study, all the openings such as windows and doors were closed, however small openings are created in order to mimic leaks from the building envelope. CFX (ANSYS, 2012) was used to run Reynolds Averaged Navier-Stokes (RANS) simulations with the RNG k- $\varepsilon$ (Yakhot et al., 1992) turbulence model. The constants for the model are as follows:

$\mathrm{C}_{1 \varepsilon}=1.42, \mathrm{C}_{2 \varepsilon}=1.68, \mathrm{C}_{\mu \mathrm{RNG}}=0.0845, \sigma_{\mathrm{k}}=0.7194, \sigma_{\varepsilon}=0.7194, \eta_{\mathrm{o}}=4.38$ and $\beta_{\mathrm{RNG}}=0.012$

The convergence criterion for each time step was that the root mean square (RMS) residuals of the momentum, enthalpy and mass conservation equations should be less than $1 \times 10^{-6}$.

\subsubsection{CFD results}

From plotting the velocity profile (Figure 6), it can be observed that air is drawn in from the ambient via the door opening. This cold air starts to heat, owing to the heat gains in the building, then rises up near the back wall and finally escapes via the atrium leakages at the top. The cold ambient air travels at Published by SCHOLINK INC. 
about $0.6 \mathrm{~m} / \mathrm{s}$ which is in line with the velocity measured in experiments. Vector plots (Figure 7) on the same plot further explains the flow pattern of air from outside into the building and further reveals the presence of a vortex, just above the stream of ambient air drawn in through the doorway.

Streamlines plotted from the main entrance doorway illustrate the pattern of travel of the ambient air. Figure 7 demonstrates how much of the ambient air makes its way to the Bistro cafe area rather than along the "Street" of the building. Yan (2010) and Chen (2011) discussed the thermal discomfort experienced by the occupants, particularly the receptionist sitting near the entrance of the doorway. The CFD study shows how the ambient air travels in laminar streamlines about 6 meters into the domain before becoming turbulent. This turbulent flow causes spiral draughts that spin out towards the location occupied by the receptionist. This then explains the cold draughts in the area next to the doorway.

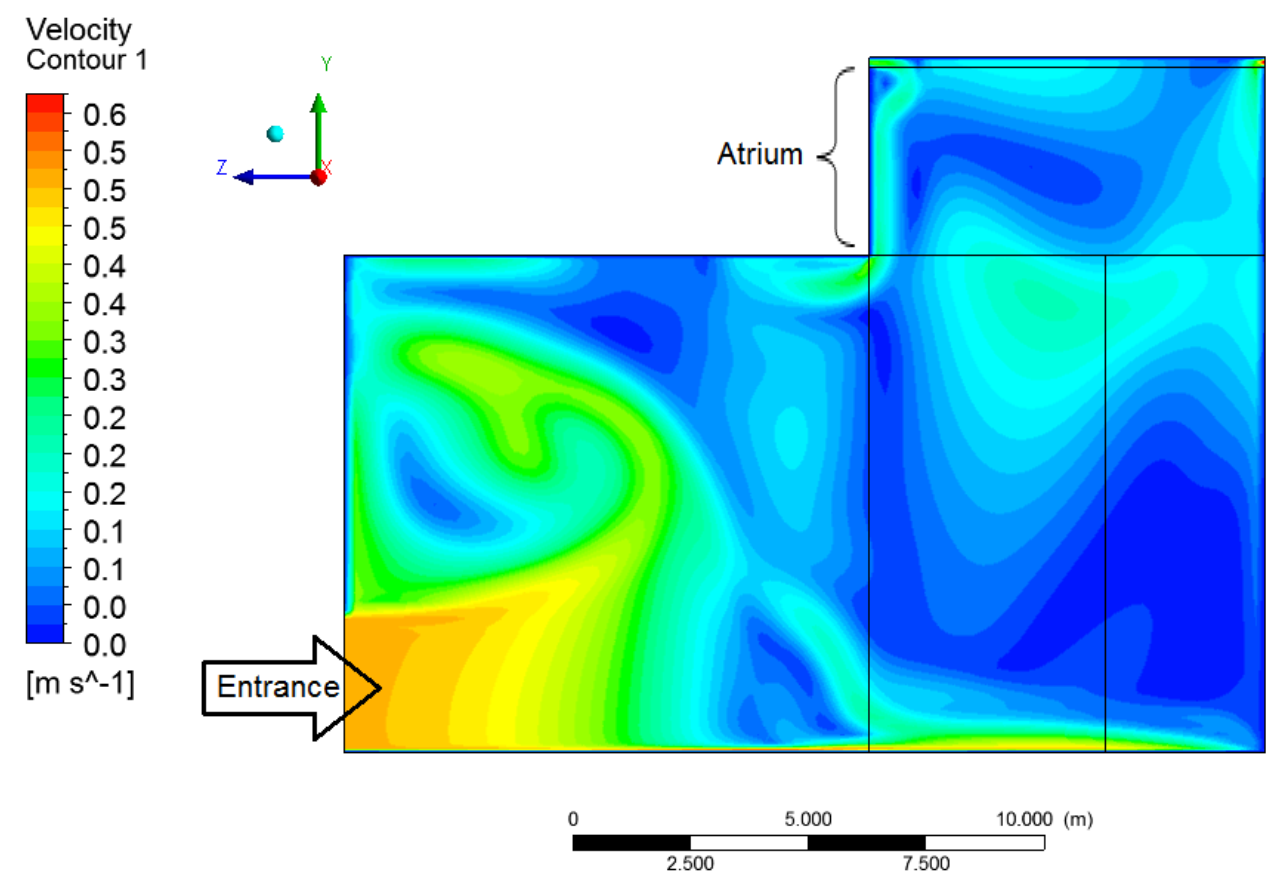

Figure 6. Velocity Profile Span Wise through the Doorway 


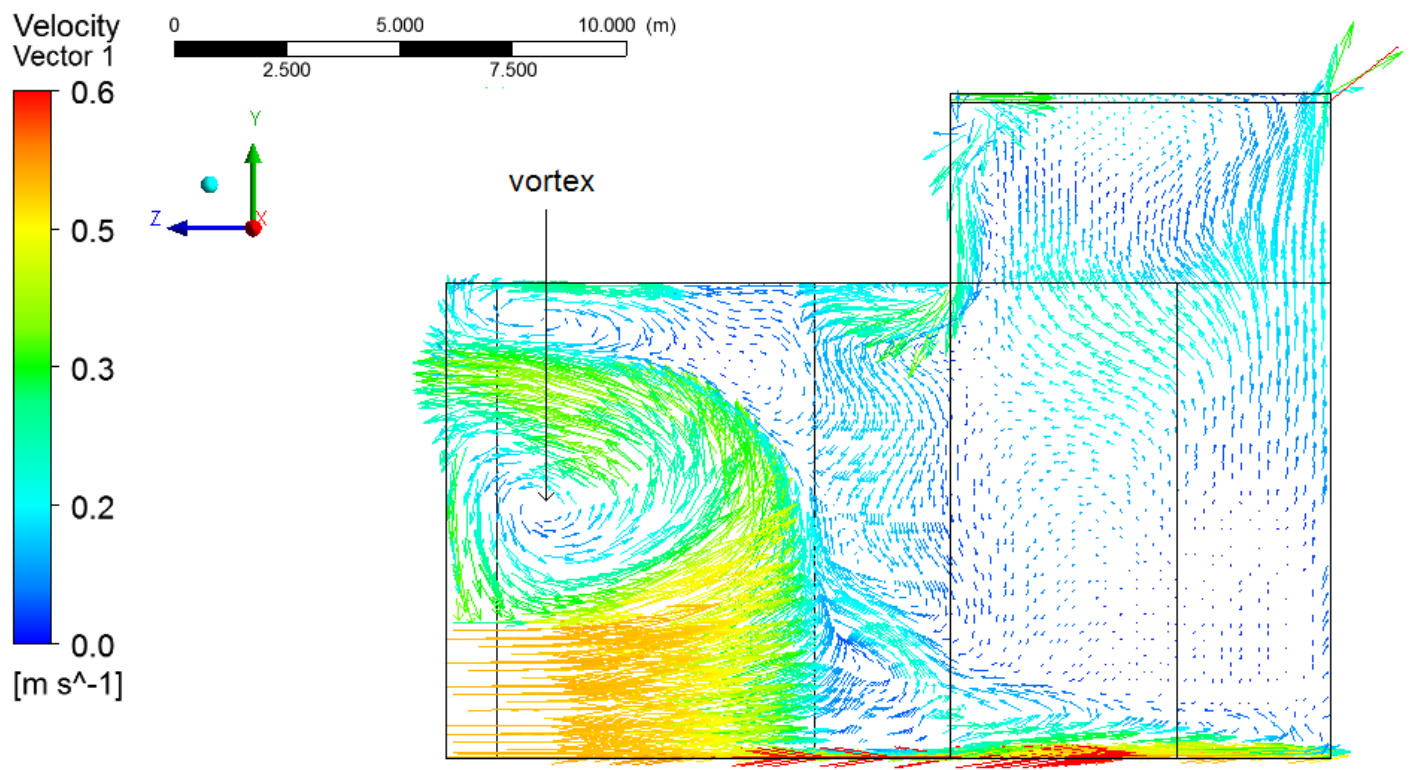

Figure 7. Vector Plots on a Plane through the Doorway

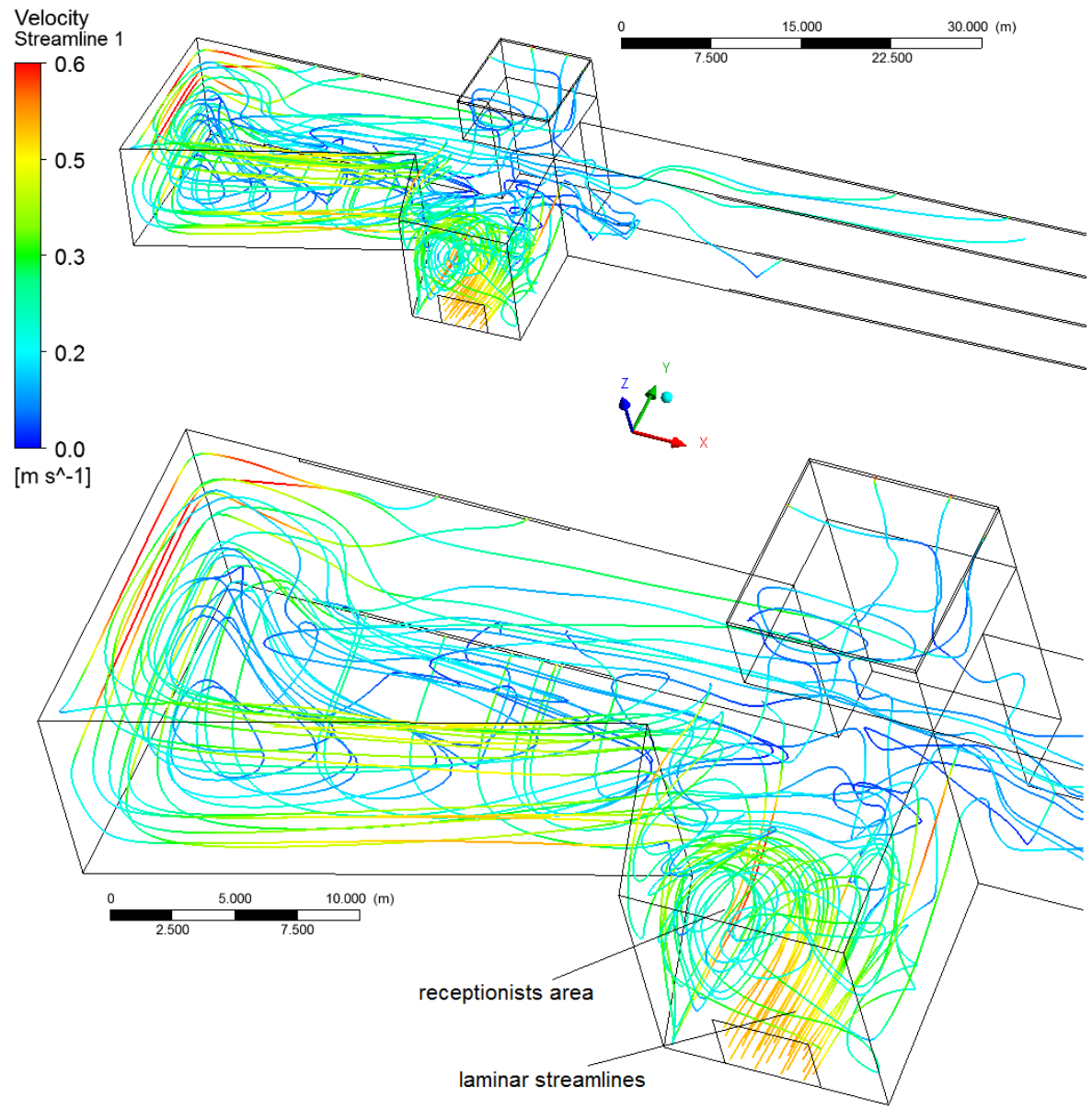

Figure 8. Streamlines in the Computational Domain Plotted from the Doorway 


\section{Discussion}

The main aim of this study was to investigate the effects of air flow movement through high use front entrance doors. A range of strategies were employed i.e., smoke testing, instrument testing, building simulation and CFD to elucidate air flow phenomenon through the vestibule doors. The main investigations of the experimentation demonstrated potential steady state ventilation heat loss of 30.7 $\mathrm{kW}$ and heat loss of $115.25 \mathrm{kWh}$ through a heating season. It also suggested that if the air movement velocity was increased to $1.0 \mathrm{~m} / \mathrm{s}$, the heat loss could be $230.5 \mathrm{kWh}$. The resultant $\mathrm{CO}_{2}$ produced ranged from $21.3 \mathrm{~kg}$ and $113.11 \mathrm{~kg}$.

The initial smoke testing suggested that front entrance vestibules can exacerbate heat energy loss by creating a "tunnel" for the air movement to be encouraged to flow. It also illustrated that the cold air could move into the building through the vestibule and hot air did not escape in an outward direction. The "tunnel" effect was also demonstrated with the outcomes in the CFD modelling when observing the laminar streamlines developed through the vestibule of the colder air entering the building. In attempting to reduce the cold airflows into the building, simulation software (IES) was used to model the building and then adapt the entrance design. The results did not appear to offer any significant reduction in energy use as identified by Cho et al. (2010) earlier. The is thought to be due to the stale air escaping the building from the outlets at the top sucks ambient air into the building regardless of the resistance that is employed to the ambient air entry.

It was established that during the heating season, cold air will flow rapidly into the building through the main entrance vestibule, owing to its original design with the heating/ventilation strategies. As this papers' design considerations may not reduce expected heat loads, other designs or strategies should be considered. With identifying laminar flows, further investigation would be recommended in reducing the impact of these. This could entail internal design proposals within the entrance/reception area, to create a separate boundary within the building being permanently pressurised using a variable speed fan. This could then resist the vortex identified in the CFD study and reduce the pressure differentials which encourage the flows into the building.

\section{References}

Allard, F. (1998). Santamouris M. Prediction methods: Natural Ventilation in Buildings: A Design Handbook (pp. 70-71). London: James \& James.

ANYS. CFX V13. (2015, July 21). Retrieved from http://www.ansys.com/Products

Artmann, N., Jensen, R. L., Manz, H., \& Heiselberg, P. (2010). Experimental Investigation of Heat Transfer During night-time Ventilation. Energy and Buildings, 42, 366-374.

Carbon Trust. (2012, January 28). Low carbon buildings. Retrieved from http://www.carbontrust.co.uk/emerging-technologies/current-focus-areas/buildings/pages/building s.aspx

Chen, Y. (2011). Monitoring Thermal Comfort and Energy consumption in a college. MSc dissertation, Published by SCHOLINK INC. 
Department of Civil and Building Engineering, Loughborough University.

Cho, H., Gowri, K., \& Liu, B. (2010). Energy saving impact of ASHRAE 90.1 vestibule requirements: Modeling of air infiltration through door openings. Oak Ridge, TN: Pacific Northwest National Laboratory: 47.

CIBSE. (2005). Natural Ventilation in Non-Domestic Buildings, Application Manual 10. London: Chartered Institution of Building Services Engineers.

Department for Environment, Food and Rural Affairs (Defra). (2012, July 30). Guidelines, GHG Conversion Factors for Company Reporting. Retrieved from http://www.defra.gov.uk/publications/files/pb13773-ghg-conversion-factors-2012.pdf

Department of the Environment, Transport and the Regions (DETR). (2012, July 30). Energy Consumption Guide 19 (ECON19)_Energy use in offices. Retrieved from http://www.cibse.org/pdfs/ECG019.pdf

Holzhauer, R. (2012). Industrial Air Curtains. Plant Engineering 1986. BSRIA Library information Centre, 16, 26-30.

Lawton, E. B., \& Howell, R. H. (1995). Energy savings using air curtains installed in high-traffic doorways, No CONF-950624. American Society of Heating, Refrigerating and Air-Conditioning Engineers. Inc., Atlanta, GA (United States).

McNally, T. (2008). Air Curtains: An open and shut case? Maintenance \& Asset Management (pp. 59-62). BSRIA Library Information Centre.

Schijndel, H. V., \& Stathopoulos, T. (2003). Simulation of air Infiltration through Revolving Doors (pp. 11-14). Eighth International IBPSA Conference, Eindhoven, Netherlands.

Stalder, L. (2009). Turning Architecture Inside Out: Revolving Doors and Other Threshold Devices (pp. 69-77). Journal of Design History, Oxford: Oxford University Press.

Wan, E. (2009). Calculating the effective air change rate through an entrance vestibule into an atrium and the effect upon energy loss and carbon dioxide emissions. MSc dissertation, School of Environmental Sciences, University of East Anglia.

Yakhot, V., Orszag, S. A., Thangam, S., Gatski, T. B., \& Speziale, C. G. (1992). In A. Physics of Fluid (Ed.), Development of turbulence models for shear flows by a double expansion technique (pp. 1510-152).

Yan, Z. (2010). Analysis and Comparison of a Dynamic Thermal Model Energy Analysis and the Monitored Energy Performance on an EPC A Rated Building. MSc dissertation, Department of Civil and Building Engineering, Loughborough University.

Yuill, G. K., Upham, R., \& Chen, H. (2000). Air leakage through automatic doors. ASHRAE Transactions, 106(2), 145-160. 